\title{
EDUCAÇÃO PROFISSIONAL NO BRASIL PÓS LDB 1996: contradições e sentidos
}

\section{PROFESSIONAL EDUCATION IN BRAZIL POST LDB 1996: contradictions and senses}

LA EDUCACIÓN PROFESIONAL EN BRASIL TRAS LDB 1996: contradicciones y significados

\author{
Francisca das Chagas Silva Lima \\ Professora Doutora da Universidade Federal do Maranhão (UFMA). \\ fransluma@fol.com.br \\ Lucinete Marques Lima \\ Professora Doutora da Universidade Federal do Maranhão (UFMA). \\ lucinete@uol.com.br
}

\begin{abstract}
RESUMO: O artigo reflete sobre a Educação Profissional no Brasil pós LDB buscando apreender os princípios e concepções fundamentadoras dos instrumentos normativos e programáticos, suas relações, contradições ou sentidos. Utiliza-se de pesquisa bibliográfica e análise documental. Considera que, nos últimos vinte anos, as políticas educacionais brasileiras aprofundam os vínculos com a lógica da reestruturação capitalista de produção e com a concepção de formação polivalente para uma estrutura de mercado de trabalho flexível, seletiva e excludente. As bases normativas da educação nacional, a partir da LDB 1996, incorporam influências desse modelo de acumulação flexível e respectivo referencial de formação por competência, e da doutrina neoliberal, no entanto, permanece a disputa e a contradição no debate acadêmico e práticas programáticas e institucionais com outras concepções de formação. PALAVRAS-CHAVE: Políticas educacionais. Educação profissional. Formação do trabalhador.
\end{abstract}

ABSTRACT: The article reflects on the Professional Education in Brazil post LDB seeking to grasp the principles and conceptions underlying normative and programmatic instruments, their relations, contradictions or senses. Bibliographical research and documentary analysis are used. It considers that, in the last twenty years, Brazilian educational policies have deepened the ties with the logic of capitalist restructuring of production and with the concept of multipurpose training for a flexible, selective and excluding labor market structure. The normative bases of national education, since LDB 1996, incorporate influences of this model of flexible accumulation and respective reference of training by competence, and of neoliberal doctrine, nevertheless, the dispute and the contradiction remain in the academic debate and programmatic and institutional practices With other conceptions of formation.

KEYWORDS: Educational policies. Professional education. Training of the worker.

RESUMEN: En este artículo se reflexiona sobre la educación profesional en Brasil después de la LDB buscando entender los principios y conceptos fundamentadoras instrumentos normativos y programáticos, sus relaciones, contradicciones o sentidos. Utiliza la literatura y el documento de análisis. Se estima que, en los últimos veinte años, las políticas educativas de Brasil profundizan los lazos con la lógica de la reestructuración capitalista de la producción y el diseño de la formación polivalente para una estructura de mercado de trabajo flexible, selectiva y excluyente. Las bases normativas de la educación nacional, de LDB 1996 incorporan influencias de este modelo de acumulación flexible y su punto de referencia para la formación de competencia, y la doctrina neoliberal, sin embargo, sigue siendo la diferencia y contr adicción en el debate académico y prácticas programáticas e institucionales con otros conceptos de entrenamiento.

PALABRAS CLAVE: Políticas educativas. La educación profesional. Formación de los trabajadores.

Artigo recebido em setembro de 2016

Aprovado em novembro de 2016 
EDUCAÇÃO PROFISSIONAL | Francisca das Chagas Silva Lima e Lucinete Marques Lima

\section{1| INTRODUÇÃO}

Nos anos de 1990, na educação brasileira, intensifica-se um movimento progressivo de vinculação da educação à lógica da produção capitalista, assentado nos processos de transformação tecnológico-organizacionais, na maximização da produtividade com redução de custos de produção, na valorização do capital e no controle sobre a força de trabalho. Do ponto de vista ideológico, essa lógica justifica-se no discurso da necessidade de formação de um trabalhador de novo tipo, demandado pelo novo modelo de acumulação vigente.

Com base na lei geral de acumulação capitalista - segundo a qual os gastos dispendidos com trabalho vivo devem ser menores em comparação com os investimentos em meios de produção, por meio da substituição do trabalho vivo pelo trabalho morto - os discursos enfatizam a necessidade de programas de qualificação do trabalhador. Especificamente, no Brasil,dissemina-se a ideia da existência de defasagem ou mesmo escassez de mão-de-obra preparada para atender às ofertas de emprego no contexto do novo mundo do trabalho.

Em face de tal realidade, a educação passou a ser então considerada (inclusive ao nível dos programas de governo) como um campo de interesse estratégico - seja para forjar as habilidades supostamente requeridas pelo novo mundo do trabalho, seja para difundir o ideário da nova ordem mundial, seja ainda para escamotear as causas objetivas do desemprego estrutural, marcante na sociedade contemporânea - justificado como sendo a expressão da falta de qualificação do trabalhador para os novos processos produtivos. Tais argumentos fazem-se presentes na história do capitalismo, tendo em vista que a burguesia não se dispõe a assumir os custos com a formação/educação do trabalhador, requerendo a presença do Estado para o estabelecimento das diretrizes formativas e da normatização dos programas e, sobretudo, para o financiamento das políticas de qualificação do trabalhador.

À luz dessa perspectiva, buscamos direcionar a análise das reformas ocorridas no campo educacional pós LDB de 1996, especialmente em relação à Educação Profissional, sem desconsiderar suas possíveis ligações com o Ensino Médio, buscando compreender na sua historicidade e contradição os fundamentos teóricos e o sentido das reformas da base jurídiconormativa da Educação Profissional com suas contradições e relações que se estabelecem na realização do objetivo de garantir as condições de valorização do capital.

Nesse contexto, também, consideramos que, nesses anos de 1996 a 2016, ocorrem mobilizações de diferentes segmentos sociais organizados (sindicatos, associações culturais e científicas e outros) que lutavam pelo processo de democratização política e do direito à educação e ao trabalho, pressionando as políticas públicas e a responsabilidade do Estado.

Esse artigo, inicialmente, analisará as reformas da Educação Profissional antes da LDB 1996, sem desconsiderar seus antecedentes do período militar e dos anos de transição democrática. Em seguida, fará uma análise dos movimentos da política educacional brasileira pós LDB até o período do governo Lula e Silva. 
EDUCAÇÃO PROFISSIONAL | Francisca das Chagas Silva Lima e Lucinete Marques Lima

\section{2 | REFORMAS DA EDUCAÇÃO PROFISSIONALANTES DA LDB 1996 NA ÓTICA NEOLIBE- RAL}

A doutrina neoliberal desenvolveu-se com a crise internacional do capitalismo dos anos 1970 e a reestruturação do processo produtivo, com implicações nas formas e relações de trabalho, e rupturas com fronteiras nacionais. Partiu da crítica do intervencionismo do Estado na economia e nas políticas sociais, considerando-o responsável pela crise fiscal e inflacionária, portanto requerendo a redução do seu tamanho e a reconfiguração de suas funções, de modo a propiciar à iniciativa privada - que na ótica dos ideólogos neoliberais tem eficiência, qualidade e produtividade - a ampliação de seu espaço de atuação.

Nessa visão, o Estado deve ser mínimo e cumprir apenas algumas funçõesem relação ao ensino comum, à saúde pública destinada aos pobres e à criação e manutenção de infraestrutura essencial ao desenvolvimento econômico, transferindo parte das responsabilidades com políticas sociais para a iniciativa privada. Parece haver uma agenda educacional globalmente estruturada em prol da acumulação do capital, sustentada por forças econômicas e políticas supranacionais e transnacionais que impõem relações de dominação e certa homogeneização das políticas educacionais dos países com a mediação dos organismos internacionais.(AFONSO, 2001 apud LIMA, 2011).

Essa agenda internacional inspirou reformas educacionais a partir da década de 80 do século passado, em países europeus e nos Estados Unidos, no quadro de crise capitalista internacional, não sendo consequência do processo de globalização nem de uma resposta indulgente ao dramático aumento da competição internacional, mas correspondendo a uma estratégia para o enfrentamento da crise causada pela queda da taxa de lucro que estava a requerer uma readequação das funções sociais do estado à nova situação da economia mundial. Essas reformas reduzem o espaço público e ampliam o espaço privado para além das atividades econômicas ao transformar em mercadoria direitos sociais (CHAUÍ, 1999).

Desse modo os pressupostos neoliberais influenciam a área da educação, com medidas de redução do Papel do Estado no seu financiamento, de ampliação dos processos de privatização, de substituição da concepção de universalidade pela concepção de equidade e de utilização do conceito burguês de competência para justificar, como natural, a seletividade e a contenção do acesso a níveis mais elevados de escolaridade. Essas medidas, dentre outras, resultam em comprometimento dos direitos alcançados e fizeram-se presente no contexto brasileiro a partir dos anos 1990.

Nesse contexto, a política educacional defendida pelos ideólogos neoliberais expressa o projeto de sociedade relacionado aos interesses do realinhamento econômico e político dos países. Nesse movimento, de âmbito internacional, percebem-se transformações nos processos produtivos organizacionais, associados ao uso intensivo de tecnologias e às medidas que visam à redução de postos de trabalho. Tal combinação tem levado a uma reconfiguração do mercado de trabalho, o qual passa a estruturar-se com um grupo central de empregados (em número reduzido, ala qualificação, de tempo integral, posição relevante e benefícios) e dois grupos periféricos com clara diferenciação entre eles - um, empregados em tempo integral de fácil substituição no mercado de trabalho e com escolarização para atividades meio; e outro, crescentemente em expansão de trabalhadores de alta rotatividade nos empregos, com baixa qualificação e sujeitos à precárias condições de trabalho e remuneração. (HARVEY, 1996).

Nos países da América Latina, entre eles, no Brasil, na década de 90 do século passado, o Banco Mundial foi o principal financiador de projetos na área educacional, condicionando o aporte de recursos ao cumprimento de metas por ele estabelecidas, tais como a redução dos gastos públicos, a desregulamentação dos mercados, a abertura econômica e a privatização das empresas estatais - estas com a finalidade de reduzir o papel intervencionista do Estado na economia. 
EDUCAÇÃO PROFISSIONAL | Francisca das Chagas Silva Lima e Lucinete Marques Lima

Nesse contexto de reestruturação produtiva e de influências neoliberais, situamos o movimento da Educação Profissional no Brasil no intervalo temporal de 1990 à aprovação da LDB de 1996. Anteriormente, no período do governo militar, com a aprovação da Lei $n^{0} 5.692$, de 11 de agosto de 1971, que trata da reforma do $1^{\circ}$ e $2^{\circ}$ graus de ensino, foi proposto como objetivo geral a formação para o desenvolvimento de potencialidades, qualificação para o trabalho e exercício da cidadania. Desse modo, a Educação Profissional inseria-se nos dois níveis de ensino - no primeiro como sondagem e iniciação e no segundo grau com o caráter obrigatório, certificando o técnico de nível técnico ou o auxiliar técnico.

Essa Lei incorporava fundamentos de uma Pedagogia Tecnicista, não resolvia o problema da dualidade formação geral e formação técnica, ajustava-se aos interesses do mercado de trabalho capitalista com demanda de trabalhadores com formação técnica e desestimulava a pressão por vagas nas instituições de educação superior. Diante das críticas e resistências, bem como da falta de condiçõesobjetivasnasescolas paradesenvolveroscursostécnicos, essa Leifoiflexibilizadapormeio da Lei $n^{\circ} 7.044$, de 1982, permitindo a existência do segundo grau propedêutico e do ensino técnico.

Outros Programas de Educação Profissional existiram em tempos de governo militar, a exemplo do Programa Intensivo de Preparação de Mão-de-Obra (PIPMO), concebido no governo João Goulart em 1963 e revitalizado em 1972, com cursos profissionalizantes para trabalhadores pouco escolarizados, inicialmente vinculado ao MEC e posteriormente ao Ministério do Trabalho. Esse Programa foi extinto em 1982. Também, por meio da Lei $n^{\circ} 6.297$, de 15 de dezembro de 1975, pessoas jurídicas poderiam deduzir do lucro tributável para imposto de renda o dobro de despesas comprovadas com projetos de formação profissional, no período-base. Mas, com a exigência de aprovação do projeto de formação pelo Ministério do Trabalho e da dedução não exceder a 10\% do lucro tributável em cada exercício financeiro, permitindo ainda transferir o excedente para os três exercícios subsequentes. Assim, tratava-se de uma renúncia fiscal prol da iniciativa privada.

Em tempos do início da redemocratização do país (1985 - 1990), a transição de um governo militar para um civil desenvolve-se numa conjuntura de crise econômica, conflitos, fragilidades institucionais e fortalecimento de movimentos sociais, favorecendo conquistas de direitos sociais, com a aprovação da Constituição de 1988 que no artigo 214 prescreve a existência de uma Lei para aprovar o Plano Nacional de Educação que articule o regime de colaboração dos entes federados para assegurar o ensino, incluindo a formação para o trabalho no inciso IV.

No entanto, a ideia de igualdade de oportunidades presente na Constituição de 1988 - conquista das lutas dos setores mais progressistas da sociedade, que defenderam o direito universal de acesso à escola pública em todos os graus e níveis de ensino, nos estabelecimentos oficiais (Art. 206) - vem sendo substituída pelo conceito de equidade, com os argumentos de que não há recursos suficientes para investir em educação para todos. Para os mentores intelectuais do Banco Mundial, a universalização do ensino resulta em desperdício de recursos, pois nem todos têm a competência acadêmica necessária para a continuidade dos estudos. Àqueles, os segmentos geralmente excluídos, como os pobres, as mulheres e as minorias étnicas, o Estado deve assegurar condições mínimas de acesso a bens e serviços sociais, fazendo justiça social com eficiência econômica.

No período de 1990 a 1992, tendo na Presidência da República Fernando Collor de Melo, o governo apresentou ao país um discurso modernizante, sintonizado com o ideário neoliberal.O programa de governo, denominado de Reconstrução Nacional, buscou atender às diretrizes estabelecidas pelos organismos internacionais, tais como a abertura do mercado nacional às empresas e produtos estrangeiros, a reforma do Estado e a restrição dos direitos sociais enunciado pelo Consenso de Washington. Esse Consenso traçou um programa ultraconservador, monetarista e de ajuste do Estado, mediante reformas que permitissem a desregulamentação da atividade econômica, privatização de empresas públicas e abertura, sem restrições, das economias (periféricas 
e semiperiféricas) ao mercado e à competição internacional. No setor educacional, o Governo Collor defendeu o atrelamento entre desenvolvimento econômico e a educação.

No entanto, nos primeiros anos de governo, o capital internacional e a burguesia nacional a ele associada começaram a perceber a incapacidade, em todos os aspectos, de o presidente Collor cumprir com esse programa reformista, diante de denúncias de corrupção e mobilizações sociais em prol do seu impeachment, que se verificou de fato. Em razão disso, no final de dezembro de 1992, assumiu a direção do Poder Executivo do país o vice-presidente Itamar Franco, nomeando como ministro da Fazenda o sociólogo Fernando Henrique Cardoso, que reunia as condições ideais para representar os interesses dos organismos internacionais e das forças do capital nacional, tanto no Ministério da Fazenda, como na condição de possível candidato à presidência da República (FRIGOTTO, 2006).

Os dois anos (1993 - 1994) do Governo Itamar Francoforam marcados por um aparente equilíbrio de forças. Aparente, porque as diretrizes da política econômica e social praticamente não sofreram grandes alterações. Teve continuidade a implementação do modelo de Estado assentado no ideário neoliberal que foi se configurando nessa década de 90 , com as mudanças sintonizadas com as forças de mercado, deflagrando o processo de ajuste da economia brasileira às exigências da reestruturação global da economia mundial. Apesar do país mal ter iniciado seu processo de reestruturação produtiva, começavam a ser disseminados conceitos importados de empresa de países capitalistas avançados, tais comolean-producion, sistema just-in-time equalidade total, que tiveram fortes reflexos, sobretudo no imaginário de empresários brasileiros, tendo alguns deles sido transportados para as políticas e práticas educacionais. Esses conceitos relacionam-se ao ideário do novo mundo do trabalho e que também se fez presente na política modernizante de liberalização e desregulamentação da economia de flexibilização dos processos de trabalho e de formação do trabalhador, etc.

Nesse período entre 1990 a 1994, assentada no discurso da necessidade de implementar uma nova ordem nas estruturas de produção de bens e serviços e da responsabilidade da educação nesse processo, em 1991, foi elaborada a proposta de Educação Profissional pela Secretaria Nacional de Ensino Técnico (SENETE) do Ministério da Educação (MEC), com o apoio da Secretaria Nacional de Ciência e Tecnologia. Essa proposta fazia parte das políticas mais amplas de desenvolvimento econômico do Governo Collor, as quais proclamavam a necessidade de investimentos na formação e desenvolvimento dos recursos humanos para que o país ingressasse num novo patamar de desenvolvimento, tal como foi feito pelos países detentores de tecnologia de ponta.

Essa linha de raciocínio expressa a visão messiânica da educação, no velho estilo da teoria do capital humano, apontando a educação profissional e tecnológica como a "salvadora da pátria". É o que vamos perceber na justificativa apresentada pela Secretaria Nacional de Educação Tecnológica (SENETE):

[A] Educação Tecnológica guarda compromisso prioritário com o futuro, no qual o conhecimento vem se transformando no principal gerador de riquezas, seu verdadeiro capital, exigindo, por sua vez, uma renovação da escola para que assuma seu papel de transformadora da realidade econômica e social do País (BRASIL,1991, p.57).

Com esse entendimento, foi idealizada a criação do Sistema Nacional de Educação Tecnológica que abrangeria todas as instituições de educação profissional do setor público federal, estadual, municipal e instituições particulares da rede Senai, Senac e Senat, conjugando ações que englobavam: qualificação ocupacional dirigida a adolescentes que não tiveram oportunidade de frequentar a escola regular; educação prática integrada ao currículo do ensino fundamental; formação técnica de nível médio nas escolas que ofertavam profissionalização em diversas áreas de conhecimento. Nessa perspectiva, foi aprovada a Lei $n^{\circ} 8.948$, de 08 de dezembro de 1994, que 
instituiu o Sistema Nacional de Educação Tecnológica, subordinado ao MEC e órgãos congêneres nos demais entes federados, com propósitos de articular a educação tecnológica entre os vários níveis de ensino e nas diversas instituições relacionadas à Política Nacional de Educação, bem como incluindo setores produtivos e a sociedade. Também, criava o Conselho Nacional de Educação Tecnológica, como órgão consultivo e de assessoramento do cumprimento de políticas e diretrizes formuladas por órgãos normativos. Ademais, transforma as Escolas Técnicas Federais em Centros Federais de Educação Tecnológica, porém com implantação gradual. Esses Centros teriam por finalidade oferecer educação tecnológica e por objetivos (em conformidade com a Lei $\mathrm{n}^{\circ}$ 8.711, de 28 de setembro de 1993, que transformou anteriormente uma instituição de ensino):

I - ministrar em grau superior:

a) de graduação e pós-graduação lato sensu e stricto sensu, visando à formação de profissionais e especialistas na área tecnológica;

b) de licenciatura com vistas à formação de professores especializados para as disciplinas específicas do ensino técnico e tecnológico;

II - ministrar cursos técnicos, em nível de $2^{\circ}$ grau, visando à formação de técnicos, instrutores e auxiliares de nível médio;

III - ministrar cursos de educação continuada visando à atualização e ao aperfeiçoamento de profissionais na área tecnológica;

IV - realizar pesquisas aplicadas na área tecnológica, estimulando atividades criadoras e estendendo seus benefícios à comunidade mediante cursos e serviços. (BRASIL, 1993).

Esse sistema, articulando as diferentes iniciativas de educação profissional, teria a responsabilidade de propor políticas, diretrizes e normas, bem como delimitar as diversas áreas de atuação dos órgãos que congregaria, de modo a compatibilizar essas áreas de atuação com os desafios da era tecnológica, contando para isso com o apoio do Comitê Nacional de Políticas de Educação Tecnológica, um órgão que não integrava o Sistema Nacional de Educação.

Para Kuenzer (1993), o teor da proposta do sistema, oficializado pela Lei, fazia ressurgir a dualidade estrutural da educação brasileira, ao conceber um sistema específico de educação tecnológica paralelo ao Sistema Nacional de Educação, reforçando concepções que separam rigorosamente ciência de tecnologia, atividade teórica da atividade prática. Em outras palavras, o pensar do fazer. Essa concepção sinalizaria a vinculação da educação a interesses imediatos e práticos, justificados pela necessidade de se diversificar a oferta de cursos de modo a atender às novas demandas do processo produtivo, mediante de uma programação permanente de formação de recursos humanos. Essa autora argumenta ainda sobre um outro ponto crítico do Sistema de Educação Tecnológica, referindo-se à distorção da política de financiamento da educação, pois, ao pleitear a ampliação do investimento público na educação tecnológica, por meio da articulação com os Ministérios da Infraestrutura, Agricultura, Saúde, Trabalho e Previdência Social, criava mecanismos de repasse de recursos públicos a segmentos do ensino voltados para a educação tecnológica, em detrimento das demais áreas de conhecimento, em especial as humanísticas, além de repassar recursos para outras instituições que não pertencem ao sistema de educação pública.

Dessa forma, pode-se deduzir que, ao comprometer a aplicação de recursos públicos com o desenvolvimento da educação de nível tecnológico, ao invés de priorizar investimentos que concorrem para a universalização da educação básica, bem como para a ampliação e melhoria da qualidade do ensino superior, como prevê a Constituição Federal de 1988, o referido Sistema Nacional de Educação Tecnológica revela sua articulação ao projeto hegemônico do capital que se beneficia da distribuição desigual e fragmentada da educação.

Em 1995, "ao assumir o governo, Fernando Henrique Cardoso já tinha um projeto amplo construído na 'conciliação' dos interesses das diversas forças representantes do capital no âmbito 
internacional, tanto para seu projeto de oito anos como para as sucessões seguintes" (FRIGOTTO, 2006, p.44). Convém destacar que a política educacional gestada pelo Ministério da Educação no governo do Presidente Fernando Henrique Cardoso foi norteada pelas diretrizes propostas pelo Banco Mundial para a educação a serem seguidas pelos países em desenvolvimento. Assim, não se pode negligenciar o fato de que as reformas educacionais, implementadas nos países periféricos da América Latina, foram realizadas sob a orientação de organismos internacionais interessados nos rumos da economia desses países.

No caso brasileiro, a recomendação mais significativa e mais contundente do Banco Mundial, quanto à Educação Profissional, é a de que os recursos financeiros incidam sobre ações de qualificação profissional de curta duração e baixo custo. Para a Educação Profissional, as proposições apresentadas - partindo da compreensão de que essa formação se constituiria em um processo prolongado e caro - enfatizam a necessidade de que essas ações sejam repassadas para a iniciativa privada (KUENZER, 1999). Esse é o discurso que passa a ser assumido pelo poder público e pelos empresários que, apoiados pela mídia, passam a defender e justificar a necessidade de que sejam implementadas mudanças nos sistemas educativos dos países, como é o caso brasileiro.

\section{3 | AS REFORMAS DA EDUCAÇÃO PROFISSIONAL PÓS LDB 1996 A 2010: concepções, relações e sentidos}

A análise reporta-se para vinte anos de gestão das políticas públicas do Estado nacional e/ ou de programa de governos, correspondendo aos períodos de governo do Presidente Fernando Henrique Cardoso, Luiz Inácio Lula da Silva e Dilma Rousseff.

Os dois períodos de governo de Fernando Henrique Cardoso (1995 - 1998 e 1999 - 2002) foram marcados por reformas do Estado e das políticas sociais. O compromisso com o projeto de hegemonia capitalista foi reforçado com a continuidade do processo de abertura da economia brasileira ao mercado internacional no seu primeiro mandato (1995-1998), com a adoção do Plano de Estabilização Econômica, que tinha como objetivo principal o controle da inflação e a desregulamentação da economia. No segundo mandato de FHC (1999-2002), ocorreu o fortalecimento dessa abertura, mediante a implementação de políticas de austeridade fiscal, a redução de salários, a privatização de estatais. Todas essas medidas representaram estratégias de ajuste neoliberal, patrocinadas pelos organismos internacionais e consubstanciadas na reforma do Estado brasileiro. Uma reforma, segundo os seus idealizadores, implementada em vista da consolidação do ajuste fiscal do Estado e da modernização da administração pública

[...] para tornar o Estado mais eficiente, mais efetivo, melhor capacitado para defender o patrimônio público, mais capaz de atender às demandas dos cidadãos a um custo compatível com as restrições econômicas impostas pelo dramático aumento da competição internacional envolvido no processo de globalização (PEREIRA 1998, p. 45).

Com a posse do Presidente Lula da Silva renasceu as expectativas de educadores de terem atendidas as suas lutas pela educação e por condições de trabalho, tendo em vista que os movimentos sociais progressistas encontravam no Partido dos Trabalhadores (PT) um canal político natural para concretizar as garantias constitucionais de direitos educacionais e acreditavam na possibilidade de uma nova era para a educação no país (SAVIANI, 2007).

Entretanto, ao longo do primeiro mandato do Governo Lula, de janeiro de 2003 a dezembro de 2006 , foram tomadas medidas que deixaram clara qual a direção sinalizada. No que se refere 
EDUCAÇÃO PROFISSIONAL | Francisca das Chagas Silva Lima e Lucinete Marques Lima

às questões econômicas e educacionais, são mantidas as orientações do governo anterior, não se constituindo em ruptura com a lógica neoliberal que norteia também a política educacional. Apesar disso, percebemos também que: "[...] novas medidas foram tomadas que implicaram modificações em relação ao que fora estabelecido no Governo FHC, alterando, em consequência, determinados aspectos da regulamentação da LDB" (SAVIANI, 2007, p. 10).

Com esse entendimento, percebemos que os movimentos da reforma educacional tiveram continuidades e diferenças na assimilação do ideário neoliberal e das reivindicações sociais. Portanto, este estudo buscou apreender concepções, relações e sentidos da Educação Profissional nos últimos vinte anos. Assim, selecionamos para análise alguns instrumentos legais e normativos vigentes nesse longo período, tais como: a Lei $n^{0}$ 9.394, de 20 de dezembro que estabelece as Diretrizes e Bases da Educação Nacional; o Decreto n 2.208, de 17 de abril de 1997, que regulamentou o parágrafo $2^{\circ}$ do artigo 36 e os artigos 39 a 42 da LDB, que dispõem sobre a Educação Profissional; o Decreto $n^{\circ} 5.154$, de 23 de julho de 2004, incorporado posteriormente ao texto da LDB, que revogou o Decreto $n^{\circ} 2.208 / 97$, regulamentando o $\S 2^{\circ}$, do artigo 36 , e os artigos 39 a 42, da LDB, incluindo as Diretrizes Curriculares Nacionais para a Educação Profissional de Nível Técnico (DCNPT/1996), que contemplam as orientações políticas, filosóficas e pedagógicas da Educação Profissional, instituídas através do Parecer $n^{\circ}$ 04, de 26 de novembro de 1999, do Conselho Nacional de Educação e da Câmara de Educação Básica (CNE/CEB n 04/1999).

Apesar das especificidades nacionais e das diferenças ideológicas partidárias desses governos, as reformas educacionais e, especificamente, da educação profissional, seguem a tendência internacional. As medidas formalizadas têm em comum a afirmação da necessidade de uma escolaridade básica mais prolongada que propicie ao trabalhador conhecimentos que lhe permitam reprofissionalizar-se, qualificar-se e atualizar-se para o exercício de funções demandadas pelo mundo do trabalho e atender à complexidade tecnológica do trabalho. Desse modo, o grau de conhecimento técnico e o nível de escolaridade do trabalhador devem ser ampliados com base numa proposta de educação profissional mais abrangente para além do adestramento nas técnicas de trabalho. Uma outra tendência generalizada nas políticas de educação profissional refere-se à opção por uma organização curricular com foco no desenvolvimento de competências.

No primeiro período de governo de Fernando Henrique Cardoso foi aprovada a Lei n 9.393, de 20 de dezembro de 1996 que definiu as diretrizes e bases da educação nacional. Nesse sentido, é importante destacar que o texto dessa LDB e os demais instrumentos jurídico-normativos e programáticos da política educacional brasileira nesse período refletem a influência das transformações no modo de produção capitalista e da doutrina do neoliberalismo, evidenciando uma articulação direta da educação com os ditames do capital.

A aprovação da Lei n 9.394 de 1996 representou a vitória de forças conservadorascontra o projeto educacional construído coletivamente pela sociedade civil organizada pela via do Fórum Nacional em Defesa da Escola Pública, que sinalizava para o desenvolvimento de uma educação básica para o mundo do trabalho nos seus múltiplos aspectos humanísticos e científico-tecnológicos.

Essa LDB de 1996 definiu dois níveis escolares (Educação Básica, organizada em três etapas e Educação Superior com especificação de níveis e abrangência de cursos) e três modalidades (Educação de Jovens e Adultos, Educação Especial e Educação Profissional). Esta última modalidade - Educação profissional - deveria integrar-se aos diferentes níveis, etapas e modalidade escolares, mas também, "às diferentes formas de educação, ao trabalho, à ciência e tecnologia" com propósitos de desenvolvimento de aptidões para a atividade produtiva. Assim, desenvolver-se-ia articulada com o ensino regular ou com formas de educação continuada em instituições específicas ou no local de trabalho. Também, as Escolas Técnicas e Profissionais poderiam oferecer 
cursos especiais abertos à comunidade, além de seus cursos regulares, sem condicionar a matrícula ao nível de escolaridade.No artigo 41, a Lei admite que o conhecimento adquirido nessa modalidade, inclusive no ambiente do trabalho, pode ser objeto de avaliação, reconhecimento e certificações para continuidade ou conclusão de estudos,valorizando as experiências práticas do aluno que já se utiliza profissionalmente de uma série de conteúdos próprios de educação profissional. Esses preceitos integram os artigos 39 a 42 da Lei, mas eles passaram por novas reformas em 2008, que destacaremos posteriormente.

Apesar de algumas conquistas inscritas nos artigos desta LDB, incorporadas dos preceitos constitucionais e do debate público, constatamos a presença de diversas lacunas e imprecisões que foram objeto de acréscimos e alterações por várias outras Leis complementares. Ademais, percebemos que, ou de modo explícito ou implícito, alguns preceitos trazem como fundamento os princípios do ideário neoliberal (evidente na ruptura da demarcação espaço público/espaço privado) e a concepção de formação de um novo perfil profissional de trabalhador, que atenda aos novos requisitos de escolarização preconizados pelo mundo do trabalho. De acordo com esses novos requisitos, o trabalhador deve ser capaz de responder com competência às exigências de modernização e reestruturação produtiva.

Tal concepção, que privilegia o desenvolvimento das habilidades específicas no processo formativo também pode ser identificada no Plano Nacional de Educação Profissional, aprovado em 1996. De acordo com o Plano, a partir do desenvolvimento de habilidades específicas, desenvolver-se-á a qualificação profissional específica para grupos de ocupações, processos ou frações da produção industrial, comercial, agrícola ou de serviços. Trata-se, aqui, de atitudes, conhecimentos técnicos e competências que garantem, a longo prazo, a empregabilidade polivalente do trabalhador. (BRASIL, 1996, p.9).

Em sequência à LDB 1996, houve a sua regulamentação pelo Decreto $n^{\circ} 2.208$ de 17 de abril de 1997 e Resoluções n 04/99 e Parecer n 16/99 que especificaram as Diretizes Curriculares Nacionais para os Cursos Técnicos de Nível Médio. Esse Decreto aprofunda a estrutura dual entre Ensino Médio e Educação Profissional.

O artigo 36 da LDB de 1996, explicitando o caráter dual do ensino médio, determina que o currículo desse nível de ensino contenha uma parte diversificada ( $25 \%$ da carga horária mínima), composta por disciplinas de natureza profissionalizante, destinadas especialmente àqueles que "desejarem" ingressar no mercado de trabalho, e, outra, integrada por disciplinas de aprofundamento do conteúdo de caráter geral, para aqueles que "tenham a intenção" de prosseguir os estudos em nível universitário. No entanto, a escola privada de nível médio não se destina à profissionalização imediata do estudante, mas à preparação para o acesso ao ensino superior. Portanto, recai sobre as escolas públicas de nível médio a responsabilidade de organizar esse currículo optativo, a ser ministrado nos centros públicos de educação profissional, ou equivalentes, seguindo a estruturação modular da Educação Profissional. Esse tipo de experiência já era vivenciado nos Centros de Formação Profissional do Sistema S, nos quais os alunos que participavam de formação de nível técnico deveriam apresentar como requisito básico a conclusão do antigo ensino de $2^{\circ}$ grau, hoje Ensino Médio. Nesses Centros de Formação Profissional, esses jovens cursavam apenas a parte profissionalizante, modalidade essa que continua sendo oferecida, principalmente, nas escolas do Sistema S, com destaque para o SENAI.

Oliveira (2005) considera que a separação entre Ensino Médio e Educação Técnico-Profissional constitui o objetivo central da reforma do sistema educacional brasileiro, fundado numa visão dicotômica que separa a formação acadêmica e a formação profissional, fundamentando os instrumentos de política educacional brasileira, desde a aprovação dos primeiros instrumentos normativos, como o Decreto-lei n4. 073/1942 que cria o Serviço Nacional de Aprendizagem Industrial (SENAI). 
Atente-se para o fato de que, nas concepções contempladas nos documentos que orientam a formação profissional, desenvolvidas no contexto atual, essa dicotomia está presente. A estrutura modular para organizar o currículo dos cursos profissionalizantes admite a realização da habilitação profissional em diferentes momentos, instituições e formas.

Além da dualidade, outra premissa básica da educação profissional, a flexibilidade, está presente. Esta possibilita à rede de ensino técnico a oferta ampla de uma formação mais ágil, voltada exclusivamente para o mercado. Para tanto, foram criadas estratégias diversificadas e diferenciadas, extremamente flexíveis, no que se refere ao percurso de formação, permitindo saídas intermediárias e aproveitamento das disciplinas ou módulos cursados em outras instituições de ensino, desde que credenciadas pelos sistemas federal e estadual de educação.

Com base em Oliveira (2005), pensamos que as saídas intermediárias e o aproveitamento dos créditos cursados em diferentes instituições de formação profissional representavam, na prática, estratégias que permitiam ao poder público justificar os baixos níveis de investimentos nessa modalidade de ensino.

Ao instituir a certificação por competência como mecanismo para o reconhecimento dos saberes tácitos dos trabalhadores, adquiridos através de experiências construídas no trabalho ou por outros meios, admitia que o percurso curricular do aluno fosse acelerado e, ainda, propiciava a ampliação da oferta de vagas, sem a necessidade de que o poder público ampliasse os investimentos na construção de escolas. Esse mecanismo é coerente, portanto, com a lógica de redução de custos, ou seja, de redução de investimentos na educação profissional, manifesta-se em todo o conteúdo do Decreto $n^{\circ} 2.208 / 97$.

Os descontentamentos com o teor desse Decreto - súmula da forma como o poder central compreendia e implementava as ações de formação profissional no país - motivaram os educadores congregados, através de suas instituições representativas, a se mobilizarem para conseguir a revogação do mesmo, reivindicando, pois, uma nova reforma do ensino médio e da educação profissional técnica, em caráter de urgência, a partir da revisão das bases teóricas em que está assentada a educação profissional, que colocasse em xeque o conteúdo ideológico do Decreto $\mathrm{n}^{\circ}$ 2.208/97, elaborado, particularmente, conforme os "humores do mercado". Segundo Ramos e Frigotto (2005), "o embate travado para revogar o Decreto n. 2.208/97 engendra uma concepção ético-política de luta entre projetos societários distintos e um projeto educativo mais amplo".

(...) trata-se, na verdade, de repudiar um decreto que expressava de maneira emblemática, a regressão social e educacional sobre a égide de um ideário neoconservador ou neoliberal e da afirmação e ampliação da desigualdade de classe e do dualismo na educação (RAMOS; FRIGOTTO, 2005, p.52)

Essas diretrizes são coerentemente articuladasnos instrumentos da política educacional brasileira e fortalecidas com o apoio da mídia, em suas reportagens sobre o mercado de trabalho, profissões e emprego, sugerindo aos jovens a busca das oportunidades de inserção nesse restritivo e competitivo mercado de trabalho. Alguns desses jovens, seduzidos pelo discurso da qualificação como garantia de empregabilidade, investem em vários cursos para poder garantirem a exigida polivalência e flexibilidade e, assim, estarem aptos para a competitividade inerente ao processo de ingresso no mercado de trabalho, ou, ainda, buscam concluir seus cursos de qualificação para poderem estar em condições de lutar pelas oportunidades de trabalho que, conforme os discursos dominantes, estão à disposição das pessoas qualificadas. Portanto, na perspectiva assinalada pela política educacional, a garantia de acesso e permanência no mercado de trabalho está diretamente relacionada ao acesso às oportunidades de qualificação e requalificação profissionais. 
Em uma pesquisa realizada por Lima (2008), essa compreensão foi de tal maneira interiorizada, como demonstram as respostas apresentadas pelos sujeitos informantes sobre quais motivos de realizarem um curso profissionalizante. Dentre as opções apontadas por 60 estudantes, os motivos foram por ordem de prioridades: $56 \%$ para ser qualificado nocompetitivo mercado de trabalho; $26,4 \%$ por acreditar que um curso profissionalizante aumenta as possibilidades de emprego; $5,4 \%$ pelo fato de estar desempregado; 3,9\% para buscar outra profissão; 3,9\% para aprender algo novo e $2,9 \%$ outros.

Como se pode depreender da ordem de prioridades estabelecidas pelos jovens para realizarem um curso profissionalizante e/ou participarem de itinerários formativos de qualificação e/ou requalificação profissional, está à incorporação da ideologia de quanto mais cursos de qualificação profissional o jovem puder participar, melhor preparado ele vai estar e maiores também serão suas oportunidades de ingresso no "competitivo" mercado de trabalho. É uma proposição absorvida facilmente pelo jovem, uma vez que está legitimada pelo poder dominante, além de possuir uma difícil contestação. Importante destacar que, posteriormente, com a expansão da educação superior que se verifica a partir de então essa expectativa tende a se ampliar para esse nível mais elevado de escolarização.

As instituições de formação profissional, com destaque para a Rede Federal de Educação Profissional, Institutos Federais de Educação Ciência e Tecnologia, Serviços Nacional de Aprendizagem Industrial (SENAI), Serviço Nacional de Aprendizagem Comercial (SENAC), Serviço Nacional de Aprendizagem do Transporte (SENAT), além das escolas das rede pública estadual, municipal e particular de ensino oferecem cursos profissionalizantes, e devem, na perspectiva sinalizada, desenvolver programas de formação profissional em perfeita sintonia com o que está sendo demandado pelo setor produtivo, privilegiando uma dimensão puramente instrumental, de enfoque centrado no desenvolvimento de competências técnico-profissionais, requerendo do sistema educacional ajustamentos aos interesses oriundos do setor produtivo.

Nesse sentido, através da Confederação Nacional da Indústria, no Documento Competitividade Industrial (CNI, 1998), o empresariado nacional criticou a fragilidade do sistema educacional brasileiro, por não formar recursos humanos para o setor produtivo. Foram apontadas falhas no sistema educacional, que produziria uma elevada quantidade de analfabetos, incapacitando, assim, a força de trabalho brasileira de ser aproveitada no desenvolvimento do modelo econômico que então se desenhava.

Carvalho (1999) considerou que a proposta pedagógica defendida pela Confederação Nacional da Indústria (CNI) buscava adequar a educação às modificações que ocorrem no sistema produtivo do país. Na aparência, é apresentada em uma perspectiva humanista, mas, na essência, reafirma o caráter utilitarista, economicista e produtivista presente historicamente em sua relação com a educação.

A fragmentação das iniciativas de Educação Profissional era visível e desenvolvia-se sob a tutela de diferentes órgãos públicos. Por exemplo, tivemos o Programa de Expansão da Educação Profissional (PROEP) no período de 1997 - 2000, que envolvia o Ministério de Educação e o Ministério do Trabalho e Emprego que financiava projetos escolares de formação básica e técnica com fins de expansão e melhorias, focado na transformação das Instituições Federais de Educação Tecnológica e na expansão do segmento comunitário; o Plano Nacional de Formação Profissional (PLANFOR), criado em 1995, vinculado ao Ministério de Trabalho e Emprego, com execução descentralizada nos entes federados. Esses programas assentavam-se em um discurso de defesa da ampliação ao acesso do trabalhador a programas de formação profissional, mas que diferentemente dos discursos que os referenciavam, eles ofereciam formações aligeiradas, contrapondo-se a um processo educativocentrado na articulação dos conhecimentos científicos e 
tecnológicos do trabalhador, viabilizando o domínio dos fundamentos científicos que presidem a produção da ciência e da técnica.

No entanto, com a posse do Presidente Lula da Silva e seu programa de governo comprometido com movimentos populares e acadêmicos, houve espaços para um maior diálogo com a sociedade. Nesse contexto foi aprovado o Decreto $n^{\circ} 5.154$, de 23 de julho de 2004, que revogou o Decreto $n^{\circ} 2.208 / 97$, mas,em seu conteúdo final, sinalizou para a persistência de forças conservadoras na busca de manutenção de seus interesses.Pode-se perceber em seu conteúdo uma política de educação profissional na direção de um projeto nacional de desenvolvimento popular e de massa. O Decreto $n^{\circ} 5.154$ buscou articular o Ensino Médio com a Educação Profissional Técnica, propondo que ocorra de forma integrada, concomitante na mesma instituição ou em instituições distintas, em instituições de ensino distintas e na modalidade a distância. Deveria ser desenvolvida por meio de cursos e programas de formação inicial e continuada, educação profissional técnica em nível médio, educação tecnológica em nível superior e pós-graduação.

No entanto, a aprovação do Decreto $n^{\circ} 5.154 / 04$, por si só, não mudou o desmonte da década de 90 do século anterior. Daí a necessidade de as instituições da sociedade, direta ou indiretamente, relacionadas com as questões do Ensino Médio e com a Educação Profissional, mobilizarem-se para que mudanças efetivas de fato aconteçam. Da parte daquele governo, reforçava-se a necessidade de sinalizar forte e claramente para o reconhecimento da importância da ampliação de matrículas do Ensino Médio e de elevação de sua qualidade, assim como também da Educação Profissional, como resposta tanto aos imperativos de um direito de cidadania e de justiça social, quanto às demandas de um processo produtivo de base tecnológica digital-molecular, que apresentava a necessidade de novos conhecimentos e domínios na formação do trabalhador. No seu segundo mandato, os dispositivos da Modalidade de Educação Profissional na LDB 1996 foram alterados pela Lei $n^{0} 11.741$, de 2008.

Outras iniciativas foram desenvolvidas nesse período de governo, tais como o Programa Nacional de Reforma Agrária, o Programa Nacional de Integração da Educação Profissional à Educação Básica, na modalidade Educação de Jovens e Adultos (PROEJA), Programa Brasil profissionalizado, Programa Escola da Fábrica e outros.

Este texto não focaliza o desenvolvimento da Educação Profissional e Técnica no governo seguinte da Presidente Dilma Rousseff em que teve grande força o Programa Nacional de Acesso ao Ensino Técnico e Emprego (PRONATEC) instituído pela Lei ${ }^{\circ} 12.513$ de 2011 numa perspectiva integradora das ações de Educação Profissional.

Em suma, apesar das medidas políticas, precisamos reconhecer a existência de uma enorme lacuna a ser preenchida gradualmente pela força do movimento da história para pensar na possibilidade de viabilizar a concretização da unidade teoria/prática, ensino/trabalho produtivo e domínio dos princípios científicos que regem a produção nos programas formativos, visando superar os pressupostos produtivistas da educação técnico-profissional e tecnológica que orientam a formação do trabalhador.

Ao analisar as políticas voltadas para a formação do trabalhador no Brasil, Frigotto (2006) destaca que as reformas e as políticas educacionais da década de 90 do século passado - orientadas interna e externamente pelos organismos internacionais - caracterizam-se por profunda regressão, sintonia com o ideário educacional expresso na Teoria do Capital Humano, em versão atualizada. Ou seja, a reforma, ancorada nos pressupostos dessa teoria, é induzida pelos organismos multilaterais - Banco Mundial (BM); Fundo Monetário Internacional (FMI); União das Nações Unidas para a Educação, Ciência e Cultura (UNESCO) dentre outros. Esses organismos elaboram regras e sinalizam novas demandas ao campo econômico, político e social, disseminando os preceitos neoliberais como saída para a crise do capitalismo. Nesse sentido, a reforma do Estado 
EDUCAÇÃO PROFISSIONAL | Francisca das Chagas Silva Lima e Lucinete Marques Lima

brasileiro é justificada como uma das condições básicas para a superação dessa crise, no bojo da qual se situam também as reformas no campo da educação. Os instrumentos normativos que se seguem no governo Lula e Silva, apesar de registrarem alguns avanços, não rompem com a lógica de formação do trabalhador nos moldes do modelo de acumulação flexível e da lógica do mercado.

\section{4 | CONSIDERAÇÕES FINAIS}

A educação profissional no país sempre foi alvo de críticas e de questionamentos tanto pelos setores empresariais quanto pelos educadores. As críticas construídas ao longo da história da educação brasileira apontam quase sempre para os preconceitos e distorções que envolvem essa modalidade de ensino. Em decorrência, sempre foi tratada com desprestígio, expressa em propostas reducionistas de educação para os pobres, sem preocupação com a qualidade da oferta de cursos e com o resultado a ser alcançado. Comumente, "e confundida como sinônimo de treinamento e de adestramento dirigidos às classes populares.

Essa tendência anunciada na LDB de 1996 relaciona educação profissional com as premissas básicas de empregabilidade e flexibilidade, privilegiando a construção de competências na perspectiva do mercado capitalista. Aponta, ainda, para um modelo curricular que favoreça aos sujeitos condições de empregabilidade e de adaptabilidade às constantes mudanças que estão ocorrendo no mundo, com reflexos na produção, na concepção e realização do trabalho.

Convém destacar, que o desenvolvimento técnico e científico avança ao mesmo tempo em que aumentam o desemprego estrutural e as desigualdades sociais. Tal realidade fica escamoteada tanto nos discursos oficiais como no discurso dos empresários, segundo os quais o mercado de trabalho está aberto e que existem vagas esperando as pessoas certas para ocupá-las. Através disso, reforça-se a ideia de que a pessoa empregável é aquela que investe na sua qualificação profissional, visando atender às necessidades do mercado.

Esse texto refletiu as proposições contempladas nos preceitos normativos para a EducaçãoProfissional, as questões e problemas que historicamente lhe são subjacentes, tais como: a falta de prioridade de investimentos; a falta de condições objetivas no que se refere a infraestrutura, recursos humanos e materiais; o descompromisso da administração dos sistemas de ensino; a adoção de currículos e práticas educativas desconectadas dos interesses dos alunos trabalhadores; ausência de políticas educacionais comprometidas de fato com a formação integral do homem, etc. Sob esse arcabouço ideológico, dá-se o ajuste do sistema educacional aos ditames e prioridades estabelecidos pelo mercado.

Nesse sentido, consideramos que as reformas educativas colocam tanto a Educação Profissional como o Ensino Médio no contexto mais amplo do processo de reestruturação produtiva, trazendo implícito e explicitamente nas intenções um entendimento das diferentes estratégias que servem de suporte ao poder do capital. Assim, a essa modalidade de ensino é atribuída a tarefa de reforço à educação geral em função da formação profissional dirigida para atender aos requerimentos de uma economia que, regida pela competitividade, tem na sua estrutura produtiva processos de trabalho que estão a exigir um novo tipo de trabalhador polivalente, capaz de trabalhar com qualidade. Contraditoriamente, visa garantir uma formação dirigida para o exercício da cidadania e como suporte à educação continuada para atender à premissa da empregabilidade. Dessa forma, a expectativa para com o Ensino Médio está na ênfase atribuída à educação geral de qualidade para atender à configuração assumida pelos novos processos produtivos, os quais trazem a marca da flexibilidade e da integração que estão a requerer um outro tipo de qualificação, cujo conteúdo pode ser dirigido tanto em função do atendimento às exigências do mercado 
EDUCAÇÃO PROFISSIONAL | Francisca das Chagas Silva Lima e Lucinete Marques Lima

formal como do mercado informal.

Compreendemos, contudo, a importância e o papel desempenhados pela ciência e pela tecnologia, que, a nosso ver, devem se constituir em instrumentos que favoreçam a análise crítica e a inserção dos sujeitos no contexto social, tendo em vista a transformação da realidade, numa perspectiva emancipatória.

A ciência e a técnica, quando incorporadas à produção de valores de uso para satisfazer às necessidades humanas de melhoria das suas condições de vida, possibilitam dilatar o tempo livre, ou tempo de efetiva escolha humana, e a técnica, ampliando os sentidos e os membros humanos. Porém, na sociedade capitalista, tanto o trabalho humano como a ciência e a tecnologia estão reduzidos à dimensão coisificada, como mercadoria que se compra e vende no mercado. Elas são ordenadas para produzir lucro para quem compra, gerencia e controla privadamente tanto a força de trabalho, como a própria ciência e a própria tecnologia (FRIGOTTO, 2005). 
EDUCAÇÃO PROFISSIONAL | Francisca das Chagas Silva Lima e Lucinete Marques Lima

\section{Referências}

BRASIL. Ministério da Educação e do Desporto. Lei $n$. 9.394 de 20 de dezembro de 1996. Estabelece as Diretrizes e Bases da Educação Nacional. Brasília, 1996.

BRASIL. Ministério da Educação e do Desporto. Conselho Nacional de Educação. Resolução n. 04. Fixam as Diretrizes Curriculares Nacionais para a Educação Profissional de Nível Técnico. Brasília, DF; 2000.

BRASIL. Ministério da Educação e do Desporto. Conselho Nacional de Educação. Resolução n, 16/99. Institui as Diretrizes Curriculares Nacionais para a Educação Profissional de Nível Técnico. Brasília, 2000.

BRASIL. Decreto Lei n. 2.208, de 17 de abril de 1997. Regulamenta o parágrafo $2^{\circ}$ do Art. 36 e os Art. 39 a 42 da Lei/9.394/96 que estabelece as diretrizes e bases da educação nacional. Brasília, DF: 1996.

BRASIL. Ministério da Educação e do desporto. Secretaria de Educação Média e Tecnológica. (SEMTEC). Reforma do Ensino Técnico. Brasília, DF: 1999.

BRASIL. MEC/SEMTEC/PROEP. Educação profissional. Legislação Básica. Brasília: MEC, 2001,

BRASIL. Decreto Lei n. 5.154 de 31 de outubro de 2004. Revoga o Decreto n. 2.208/1997, MEC/CNE, Brasília: 2004.

CARVALHO, Celso do Prado Ferraz. A educação cidadã na visão empresarial: o telecurso 2000.Campinas: Autores Associados,1999.

CHAUÍ, Marilena.Uma ideologia perversa. Folha online: São Paulo, 1999.

CNI. Competitividade e crescimento: a agenda da indústria. Rio de Janeiro, Confederação Nacional da Indústria. 1996.

DOURADO, Luiz Fernando. O público e o privado na agenda educacional brasileira. In: FERREIRA, Naura Syria Carapeto; AGUIAR, Márcia Ângela da S. (Orgs). Gestão da educação: impasses perspectivas e compromissos. São Paulo: Cortez, 2006.
FRIGOTTO, Gaudêncio. Anos 1980 e 1990: a relação entre o estrutural e o conjuntural e as políticas de educação tecnológica e profissional. In: FRIGOTTO, Gaudêncio; CIAVATTA, Maria. A formação do cidadão produtivo: a cultura de mercado no ensino médio técnico. Brasília: MEC/INEP, 2006

FRIGOTTO, Gaudêncio. O ensino médio: construindo uma proposta para os que vivem do trabalho. São Paulo: Cortez, 1994.

FRIGOTTO, Gaudêncio A reforma do ensino técnico no Brasil e suas consequências. In: FERRETTI, Celso João et al. (Org). Trabalho, formação e currículo: para onde vai a escola? São Paulo: Xamã, 1999.

FRIGOTTO, Gaudêncio. O ensino médio e profissional: as políticas do estado neoliberal. São Paulo: Cortez, 1997.

LIMA, Francisca das Chagas Silva Lima. A formação técnico-profissional face aos processos de reestruturação produtiva maranhense e às diretrizes legais. Tese (Doutorado em Educação). Universidade Federal do Ceará - UFC/Faculdade de Educação -FACED/Programa de Pós-Graduação em Educação Brasileira. Fortaleza CE, DEZ 2007. 215p.

LIMA, Lucinete Marques. O processo de autoavaliação da UFMA (2004-2006) no contexto regulatírio da educação superior. Tese (Doutorado em Educação). Programa de Pós-Graduação em Educação. UnespMarília. 2011. 283p.

GRAMSCI, Antonio. Os intelectuais e a organização da cultura. Rio de Janeiro: Civilização Brasileira, 1985.

HARVEY, David. Condição pós-moderna. 6.ed. São Paulo: Loyola, 1996.

OLIVEIRA, Elenilce Gomes de. Novos caminhos na educação educação profissional brasileira? In: SOUZA, Antonia; OLIVEIRA, Elenilce Gomes de. (Orgs). Educação profissional: análise contextualizada. Fortaleza: CEFET-CE, 2005.

SAVIANI, Dermeval. Da nova LDB ao FUNDEB. Campinas: Autores Associados, 2007 